Article

\title{
Optimization of Drilling Layouts Based on Controlled Presplitting Blasting through Strata for Gas Drainage in Coal Roadway Strips
}

\author{
Zhicheng Xie ${ }^{1,2}$, Dongming Zhang ${ }^{1,2, *}$, Zhenlong Song ${ }^{1,2}$, Minghui Li ${ }^{1,2}$, Chao Liu ${ }^{1,2}$ \\ and Dongling Sun ${ }^{3}$ \\ 1 State Key Laboratory of Coal Mine Disaster Dynamics and Control, Chongqing University, \\ Chongqing 400030, China; xiezhicheng@cqu.edu.cn (Z.X.); zhenlongsong@cqu.edu.cn (Z.S.); \\ cqumhli@vip.163.com (M.L.); $20142002009 @$ cqu.edu.cn (C.L.) \\ 2 College of Resources and Environmental Sciences, Chongqing University, Chongqing 400030, China \\ 3 Gas Research Institute, Chongqing Research Institute of China Coal Technology and Engineering Group \\ Corp, Chongqing 400037, China; cqsdl@126.com \\ * Correspondence: zhangdm@cqu.edu.cn; Tel.: +86-023-6511-1228
}

Received: 3 June 2017; Accepted: 15 August 2017; Published: 18 August 2017

\begin{abstract}
The controlled presplitting blasting technique is widely used in mining engineering to improve the permeability and gas extraction efficiency of coal seams. One of the key factors is the appropriate arrangement of the blasting and drainage holes, which can help improve the gas drainage quantity. To optimize the drilling layout to enhance gas-drainage efficiency, a series of controlled presplitting blasting tests were conducted at the Pingdingshan No. 8 coal mine. Based on the analysis of variations in stress and longitudinal-wave velocity of the coal in different blasting ranges, the results show that the stress on the coal at a distance of $1 \mathrm{~m}$ from the blasting hole decreased significantly after blasting; thus, the coal exhibited negligible bearing capacity and the longitudinal-wave velocity decreased by $56 \%$. However, the coal exhibited particular bearing capacity at a distance of $3 \mathrm{~m}$ away from the blasting hole, and the longitudinal-wave velocity decreased by $35 \%$. The stress and longitudinal-wave velocity at a distance of $5 \mathrm{~m}$ from the blasting hole were unaffected by the blasting. The blasting integrity rate of coal $k_{v}$ was defined to characterize the effect of blasting on the coal-seam fracture. The effective cracking and effective influence radii of blasting under these working conditions were predicted to be in the ranges 3.3-3.4 $\mathrm{m}$ and 7.2-7.3 m, respectively. According to the test results, the borehole layout was optimized in the field testes for gas drainage in coal roadway strips, and the amounts of pure gas extracted after blasting were thus increased by 1.54-2.24 times the amount before blasting.
\end{abstract}

Keywords: mining engineering; controlled presplitting blasting; gas pre-drainage; longitudinal-wave velocity; drilling layout

\section{Introduction}

With the increasing depths of coal mines, coal seam conditions, particularly low permeability and high gas pressure, have become more complicated, thereby increasing the risk of coal and gas outbursts [1-3]. Several shallow and non-outburst coal seams have gradually turned into outburst-prone coal seams [4]. The applicability of the protective layer is gradually reduced, and the gas pre-drainage becomes the main regional measure in preventing coal and gas outbursts $[5,6]$. As the permeability of the coal seam is low, it is inefficient to drain gases only through drilling. Pressure-relief technology is usually applied to improve the permeability of coal seams, and subsequently strengthen the effect of gas extraction [7-9]. 
Controlled presplitting blasting is a type of non-falling coal (rock) blasting method aimed at improving the level of coal (rock) fissures [10]. As the method can be used to effectively improve the permeability of the coal seam, it is often combined with drilling to pre-drain gas, thus significantly reducing the drilling density and time required to drain the gas. This combination is widely used in processes such as in-seam gas draining [11], rock cross-cut coal uncovering [12], coal roadway driving $[13,14]$, and top-coal mining $[15,16]$.

Two different functional holes exist in the controlled-presplitting-blasting technique: a blasting hole and a drainage hole. Here, the drainage hole performs two functions in the controlled presplitting blasting to help relieve pressure and improve the permeability of coal seam. First, it functions as a control hole to provide a free surface for blasting and guiding the blasting energy. Owing to the existence of control holes, auxiliary free surfaces are added around the blasting hole so that the direction of the connection between the blasting and control holes becomes the direction of the least resistance line. It's the inevitable result that the detonation wave mainly propagates toward the control hole. Second, as a circulation hole, the drainage hole provides a channel for coal-seam gas migration after blasting [11]. Hence, a reasonable drilling layout is essential to effectively increase the amount of gas drainage. If the blasting hole is too close to the drainage hole (or blasting hole), the crack propagation range overlaps with each other, and the blasting effect cannot be fully realized, thus increasing the borehole density and raising costs. In contrast, if they are far apart, the drainage hole cannot provide a free surface effectively, and the crack cannot penetrate through the hole, thus reducing the gas-drainage effect [17]. Zhu et al. proposed a coupled multi-physical model for the interaction between the blasting damage to the coal seam and gas flow. Based on this model, they numerically simulated the effects of blasting on draining gas in a coal seam [18]. Li et al. used the AUTODYN software to study two adjacent borehole blasting effects and their mutual influence [19]. Zhou et al. analyzed the dynamic variations in blasting stress waves of different drilling intervals using a numerical simulation and obtained an optimal spacing required to form uniform fissures and maintain the same high destruction scope with the control hole [17]. Wang et al. employed theoretical analysis and LS-DYNA3D numerical simulation to establish a deep-hole pre-split blasting model and analyze the break scope due to the high-energy explosion stress wave. Based on the simulation results, the blasting parameters were optimized [20]. Gong et al. established calculation models for blasting through strata. Using numerical simulations and verification tests conducted on the coal mine, they discussed reasonable layouts for the drainage and blasting holes of the soft coal seam and coal-rock media, respectively [21,22]. Liu et al. studied the influence of different diameters and depths of the borehole layout on the effect of orifice pre-splitting blasting on crack propagation in the coal seam by employing ANSYS/LS-DYNA software [23]. The aforementioned studies on reasonable borehole layouts were largely conducted using theoretical or numerical simulations, and many parameters were simplified or ignored accordingly. However, site conditions such as the occurrence of coal seams, metamorphic degree of coal, and development of coal and rock structures are even more complicated and anisotropic [24-26], lead to the ideal research results that are often different from the observed blasting effects.

In this study, tests on controlled presplitting blasting through strata were conducted at the Pingdingshan Tianan Coal Co. Ltd. No. 8 coal mine. The influences of the blasting radii were studied by analyzing the variations in specific distance stress and longitudinal-wave velocity around the blast site. Finally, based on the research results, the arrangements of the drainage and blasting holes in the working face were optimized. The controlled presplitting blasting through the strata for gas drainage in coal roadway strips were then conducted to investigate the effects of gas drainage under the new drilling mode arrangement.

\section{Research Overview}

The Pingdingshan No. 8 coal mine of Pingdingshan Tianan Coal Co. Ltd. is a coal and gas outburst mine located in the east of Pingdingshan (Henan Province, China, Figure 1). The $\mathrm{Wu}_{9,10}$ coal 
seam is mined in the No. 14160 working face. The coal seam section has an elevation ranging from -380 to $-490 \mathrm{~m}$, and a buried depth ranging from 499 to $633 \mathrm{~m}$. The thickness of the coal seam is ranges between 3.75 and $4.8 \mathrm{~m}$, with an average thickness of $4.0 \mathrm{~m}$. The dip angle of the coal seam exhibits the trend of West-slow and East-steep, which is generally in the range of $18-25.6^{\circ}$, with an average of approximately $21^{\circ}$. The roof of the coal seam is made up of gray sandy mudstone, while the strip and immediate floor are made up of fine sandstone and dark-gray mudstone, respectively.

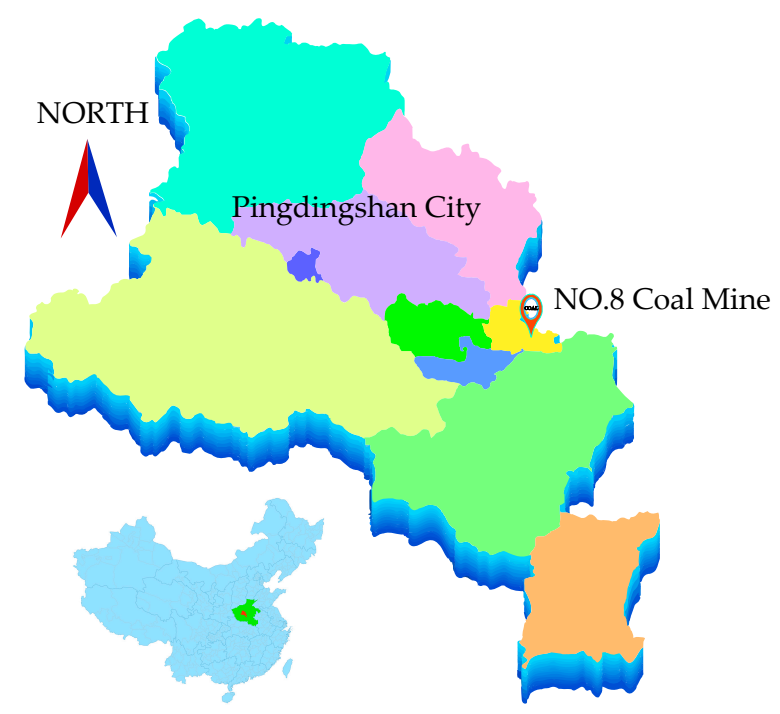

Figure 1. Geographic position of the coal mine.

The $\mathrm{Wu}_{9,10}$ coal seam has an outburst risk with an original gas pressure of $1.0 \mathrm{MPa}$ and a gas content of $13 \mathrm{~m}^{3} / \mathrm{t}$. To ensure the safety of the $\mathrm{Wu}_{9,10}-14160$ roadway excavation, the $\mathrm{Wu}_{8}$ -14160 roadway, which is located above the $\mathrm{Wu}_{9,10}-14160$ roadway, is used as a gas-drainage roadway to pre-pump gas in $\mathrm{Wu}_{9,10}-14160$ roadway strips. The vertical and horizontal distances between the gas-drainage roadway and $\mathrm{Wu}_{9,10}$ coal seam (or $\mathrm{Wu}_{9,10}-14160$ roadway) are $12.5 \mathrm{~m}$ and $15.4 \mathrm{~m}$, respectively. Figure 2 shows the relative position of the roadway.

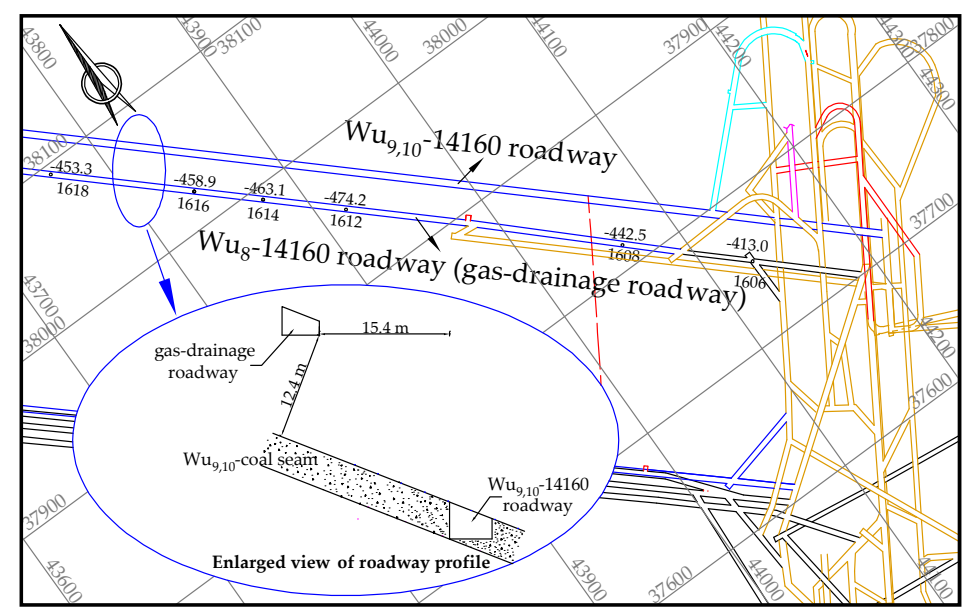

(a)

Figure 2. Cont. 


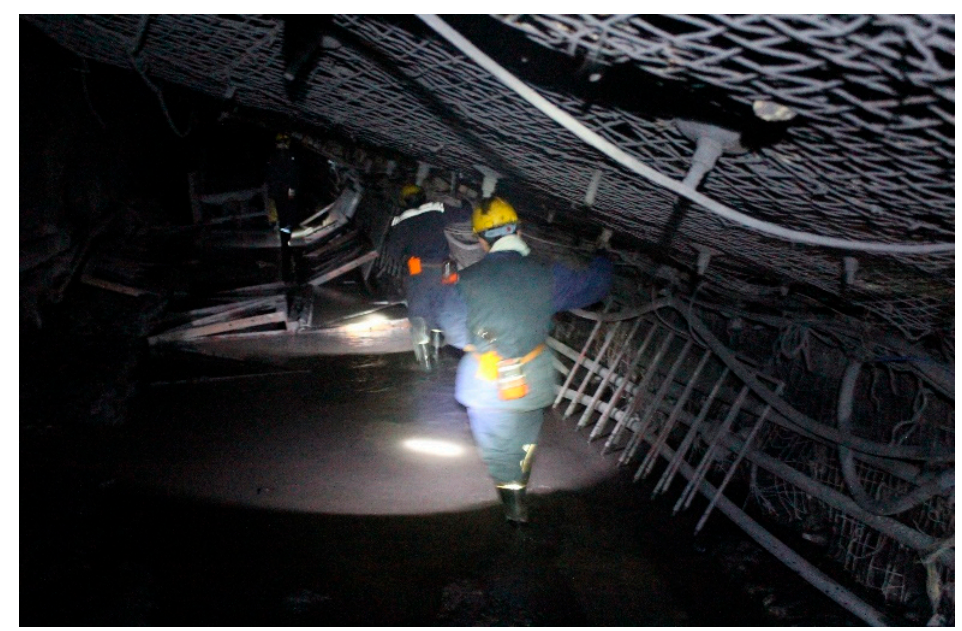

(b)

Figure 2. Tunnel arrangement: (a) Roadway design location of $\mathrm{Wu}_{9,10}$ working face; (b) Image of gas-drainage roadway.

\section{Measurement and Analysis of Blasting-Influence Radius}

\subsection{Division of Blasting Influence}

Blasting-induced cracking is the result of a combination of explosion waves, explosion gases, geo-stresses, and gas pressures [17]. After the explosion, a high-peak shock wave is generated in the coal around the blasting hole. The shock wave propagates and moves along the blasting hole to crush the coal, and subsequently forms the crush zone. Following the shock wave, the stress wave attenuates along the radial propagation. At this point, the peak value of the stress wave is still higher than the dynamic compressive strength of the coal; thus, the coal undergoes compression and forms the crack zone. The stress wave decays rapidly during the propagation process, and when the peak value is lower than the compressive strength of the coal, the stress wave can only cause the coal body to vibrate. As the explosion wave spreads, the high-temperature and high-pressure explosion gas, along with the gas in the coal, rapidly wedges into the initial crack generated by the explosion and extends the crack in a quasi-static form. The fissure continues to extend (the boundary of the crack zone) until the burst-gas pressure decreases below the geo-stress and coal strength. It is generally accepted that the boundary of the crack zone is the effective cracking range of the blasting [27]. Thus the drainage hole can be employed in this range, and the free surface can be effectively provided. The blasting energy can be guided toward the control hole furthest, and the crack can be fully extended to relieve the pressure and increase permeability.

\subsection{Experiment Process}

A crossing borehole was drilled from the gas-drainage roadway to the bottom of the coal seam, which serves as a blasting hole termed as A. Similarly, parallel boreholes were drilled along the gas-drainage roadway axis at distances of $1 \mathrm{~m}, 3 \mathrm{~m}$, and $5 \mathrm{~m}$ from the blasting hole, to serve as observation holes termed $\mathbf{B}, \mathbf{C}$, and $\mathbf{D}$, respectively. Table 1 and Figure 3 present the drilling parameters and locations, respectively.

Table 1. Drilling parameters for influence-range determination.

\begin{tabular}{cccc}
\hline Diameter $(\mathbf{m m})$ & Depth $(\mathbf{m})$ & Dip Angle $\left(^{\circ}\right)$ & Orifice Height $(\mathrm{m})$ \\
\hline 94 & 25.8 & -62 & 0.3 \\
\hline
\end{tabular}




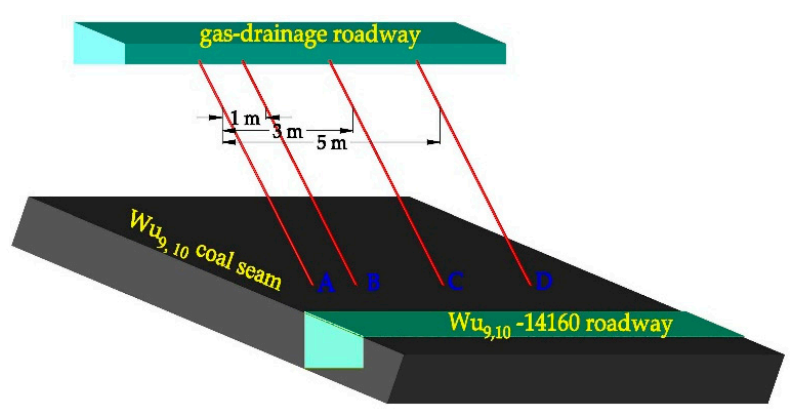

Figure 3. Borehole layout for influence-range determination.

Each observation hole was fitted with a set of borehole stressmeter to observe the changes in the coal-seam stress before and after blasting. The borehole stressmeter (model ZLGH-40, Loadcell Sensor Technology Co. Ltd., Taian, China) is a type of vibrating wire sensor with a special structure that can be used to measure changes in the coal-reserve stress of the coal pillar or to measure the rock or soil foundation pit resulting from the changes in the stress before and after excavation. It has a maximum measurement range of $40 \mathrm{MPa}$, accuracy of $1 \% \mathrm{FS}$, and repeatability of $0.4 \% \mathrm{FS}$. This type of stressmeter is easy to install, and can be used directly to read and store stress values, which is used with the GSJ-II type computer tester (Loadcell Sensor Technology Co. Ltd., Taian, China). During installation, the stressmeter was placed in the middle of the coal seam through the combined external and internal sleeve rods, and the movable block of the sensor was aligned with the drilling connection to monitor radial stress changes in the coal. The internal rod was twisted clockwise, squeezing the oil so that the stressmeter was actively coupled with the coal body, and a certain initial stress was first applied to the coal body.

Permitted emulsion explosives for coal mine were used in this experiment. The blasting hole was provided with ten explosive cartridges, three of which were also used as primer cartridges. Each primer cartridge was inserted into two instantaneous electric detonators interconnected in parallel, and the primer cartridge was connected in series with others. Using the PVC pipe as casing, the explosive cartridges and detonators were loaded into the PVC pipe and sent to the part of the coal seam. The remaining part of the PVC tube was then completely sealed by stemming materials. Figures 4 and 5 show the charge structure in the blasting hole and the parallel-series connection of the electric firing network, respectively.

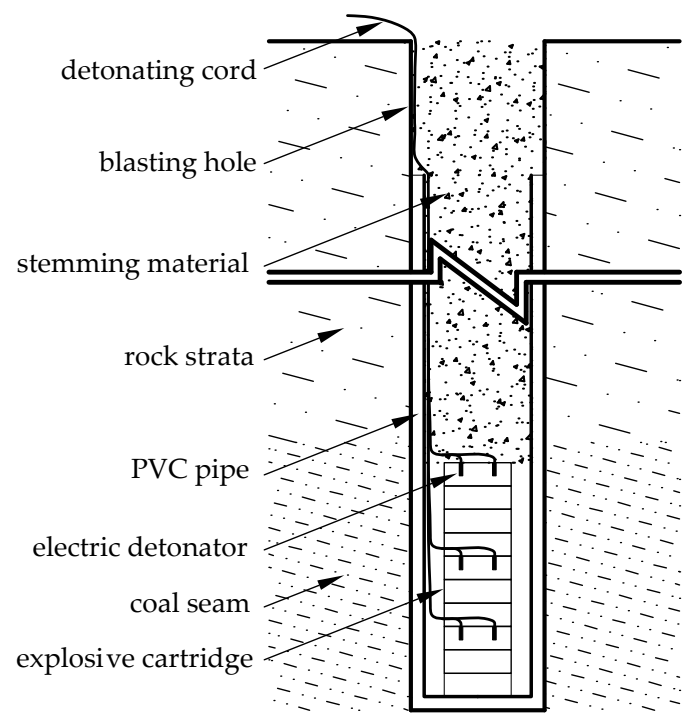

Figure 4. Charge structure in the blasting hole. 


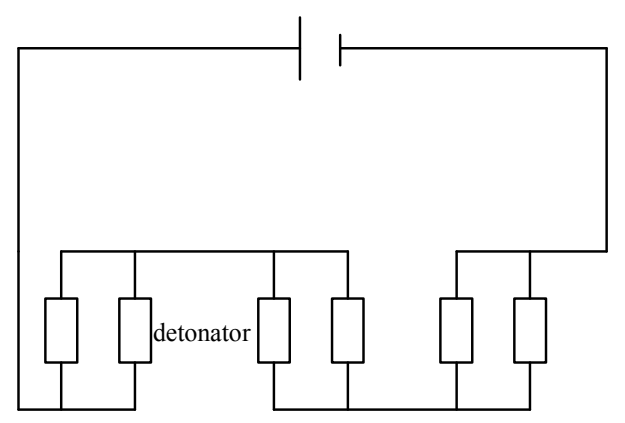

Figure 5. Parallel-series connection of electric firing network.

The longitudinal-wave velocities before and after blasting between adjacent drilling holes (A-B, B-C, and C-D) were measured using the JL-IUCA6(A) nonmetallic ultrasonic detector (Wuhan Conourish Engineering Exploration Technology Development Co. Ltd., Wuhan, China), which can be used to detect the longitudinal-wave velocity of the rock mass and rock-loose circle of the tunnel. This device is equipped with an intelligent automatic control transceiver circuit. The full combination test, which is included in two holes for one section, three holes for three sections, and four holes for six sections, can be conducted simultaneously in a lifting process without changing the position of the probe with respect to the detector tube. The maximum penetration depth of this device is up to $100 \mathrm{~m}$, and one-, three-, and six-section profile test information, such as waveform, wave train, wave velocity, and amplitude, can be observed synchronously using a colored LED screen.

\subsection{Analysis of Test Results}

\subsubsection{Stress Analysis}

Before the blasting, the initial readings of the stressmeter were 12.68 to $13.45 \mathrm{MPa}$, which are equivalent to the in-situ stress value in this direction. Figure 6 shows the variations in stress after blasting.

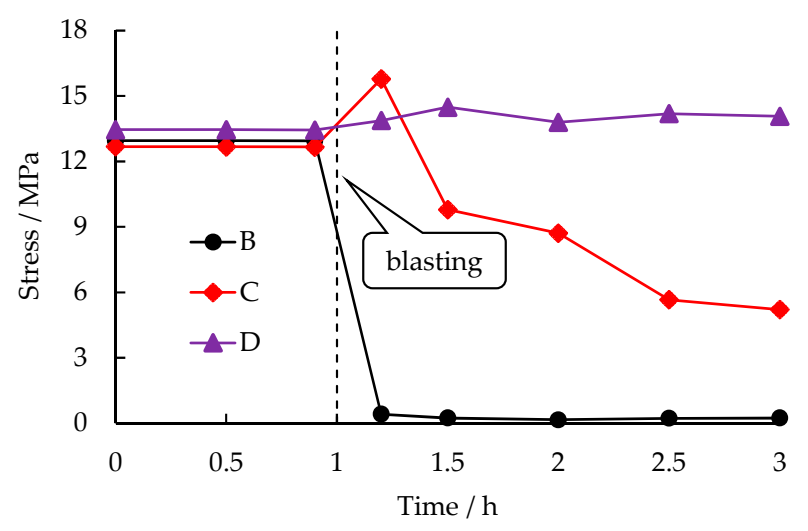

Figure 6. Variation in stress exerted on the coal body at different positions from blasting.

Figure 6 shows that although the process of cracking coal via blasting was very short, a stress redistribution occurred in the coal and a new equilibrium was achieved after a long period of time. After blasting, the stresses in the coal body at distances of $1 \mathrm{~m}$ and $3 \mathrm{~m}$ from the blasting hole decreased significantly, but the degree of change differed. The stress in the coal body suddenly dropped to zero near the blasting hole at a distance of $1 \mathrm{~m}$ (Observation hole $\mathbf{B}$ ) because of the strong shock waves generated by the explosion. The coal was quickly compressed and destroyed, resulting in severe crushing and the loss of carrying capacity. The stress in the coal body at a distance of $3 \mathrm{~m}$ 
from the blasting hole (Observation hole $\mathbf{C}$ ) eventually decreased below the original stress level of the rock, indicating that the stress wave and explosion gas helped crush the coal body within this range. However, the degree of breakage was less than that observed within a distance of $1 \mathrm{~m}$ from the blasting hole, where the coal body still had a certain carrying capacity. Because of the redistribution of coal seam stress after blasting, the pressure relief in the coal around the blasting hole led to a temporary increase in the stress of the coal at a distance of $3 \mathrm{~m}$ from the blasting hole. The stress concentration then continuously and radially moved farther away, which caused the hole wall to move backwards, thereby reducing the pore size and stress of the coal body. Eventually, the radius of the pressure relief area gradually increased. Because of the rapid attenuation of the stress wave and dissipation of explosive gas, the peak stress of the stress wave after propagating at a distance of $5 \mathrm{~m}$ (Observation hole $\mathbf{D}$ ) was lower than the dynamic compressive strength of the coal body; thus, the coal body experienced only minor vibration and did not completely break. Therefore, the stress in the coal seam did not changed significantly; the stress was only slightly higher than that before the blasting under the influence of in-situ stress redistribution. The monitoring results of the stressmeter show that the effective cracking radius of the blasting hole should be in the range of 3-5 $\mathrm{m}$ under working conditions.

\subsubsection{Analysis of Longitudinal-Wave Velocity}

The intactness index of rock mass $K_{v}$ can be used to represent the physical and mechanical properties of the rock mass, which is an indispensable parameter in engineering design. The intactness index of rock mass, also known as the fissure coefficient, is the square of the ratio of the longitudinal-wave velocity of the rock mass to the intact rock [28], expressed as follows:

$$
K_{v}=\left(\frac{V_{p m}}{V_{p r}}\right)^{2}
$$

where $V_{p m}$ is the longitudinal-wave velocity of the rock mass $(\mathrm{m} / \mathrm{s})$, and $V_{p r}$ is the longitudinal-wave velocity of the intact rock $(\mathrm{m} / \mathrm{s})$.

The longitudinal-wave velocity of the coal and rock mass is the longitudinal-wave velocity of the elastic wave propagating in the coal and rock mass in a certain space, which is not only related to lithology, but also related to the coal-rock structure, pore-fissure development, and degree of rock-weathering. However, for the particular coal and rock mass, to a certain extent, the variation in longitudinal-wave velocity can be used to reflect the degree of fissure development [29]. The intactness index of the coal body before and after blasting are expressed as $K_{v 1}$ and $K_{v 2}$, as follows.

$$
K_{v 1}=\left(\frac{V_{p m 1}}{V_{p r}}\right)^{2}, K_{v 2}=\left(\frac{V_{p m 2}}{V_{p r}}\right)^{2}
$$

where $V_{p m 1}$ and $V_{p m 2}$ are the longitudinal-wave velocity of the coal body before and after blasting, respectively.

The blasting integrity rate of coal $k_{v}$ is defined as the ratio of the intactness index of the coal after and before the blasting, which is used to characterize the effect of blasting on the cracking of the coal body:

$$
k_{v}=\frac{K_{v 2}}{K_{v 1}}=\frac{\left(\frac{V_{p m 2}}{V_{p r}}\right)^{2}}{\left(\frac{V_{p m 1}}{V_{p r}}\right)^{2}}=\left(\frac{V_{p m 2}}{V_{p m 1}}\right)^{2}
$$

By definition, the magnitude of $k_{v}$ is related to the propagation velocity of the longitudinal wave in the coal before and after the blasting, which is generally in the range of $0-1 . k_{v} \rightarrow 1$ shows that the integrity of the coal body is basically unchanged and the fracture is not extended after blasting. 
In other words, the blasting had no effect on the coal body. In contrast, $k_{v} \rightarrow 0$ shows that the coal body is severely broken after blasting, and the blasting had a strong effect on the coal seam.

Table 2 lists the measured longitudinal-wave velocity of the coal seam between the adjacent holes and calculation results for $k_{v}$ before and after the blasting.

Table 2. Measured longitudinal-wave velocity $(\mathrm{m} / \mathrm{s})$ and calculated $k_{v}$.

\begin{tabular}{cccc}
\hline Position & A-B & B-C & C-D \\
\hline Before blasting & 1437 & 1395 & 1411 \\
After blasting & 632 & 903 & 1096 \\
$k_{v}$ & 0.19 & 0.42 & 0.60 \\
\hline
\end{tabular}

Table 2 indicates that the three coal seams in the adjacent holes were fragmented but the degrees of fragmentation were different. With increasing distance from the blasting hole, the degree of coal fragmentation gradually decreased. The blasting integrity rate of the coal was only 0.19 within a distance of $1 \mathrm{~m}$ from the blasting hole. Moreover, the wave-velocity reduction was greatest, approximately 2.6 times the decrease in wave velocity in the range of $3-5 \mathrm{~m}$ and approximately 1.6 times that in the range of $1-3 \mathrm{~m}$. The wave velocity in the coal seam was reduced to $903 \mathrm{~m} / \mathrm{s}$ at a distance of 1-3 $\mathrm{m}$ from the blasting hole, and the descending magnitude was approximately 1.6 times that in the range of 3-5 m. The wave-velocity reduction in the range of $3-5 \mathrm{~m}$ in the coal seam was minimal, and the blasting integrity rate of the coal was the highest. Thus, the coal was least fragmented.

The measured longitudinal-wave velocity between the two holes was assumed as the actual velocity at the midpoint of the two holes. Thus, the blasting integrity of the coal in the two holes can be used to analyze the characteristics at the midpoint of the two-hole connection. Figure 7 shows the change in the blasting integrity of the coal with respect to distance from the blasting hole.

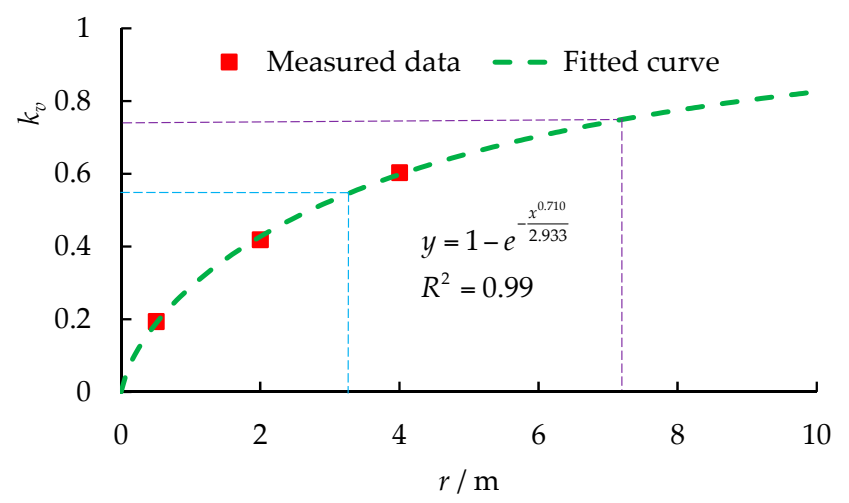

Figure 7. Variation in blasting integrity rate $k_{v}$ with respect to distance $r$.

Based on the measured data, along with the variation characteristics of the blasting integrity ratio of the coal; which indicates that the value is 0 at the blasting point $(0 \mathrm{~m})$ and is close to 1 at infinity $(\infty \mathrm{m})$; the curve of the blasting integrity of coal $k_{v}$ was fitted with respect to blasting distance $r$, as shown in Figure 7.

According to the Standard for Engineering Classification of Rock Masses [30], a rock mass with an intactness index $K_{v} \geq 0.75$ is considered an intact rock mass. Similarly, it is considered that the coal seam with the blasting integrity rate $k_{v} \geq 0.75$ was not effectively influenced by the explosion. Hence, the blasting integrity rate of coal at $k_{v}=0.75$ can be classified as the effective influence range of the blasting. The fitting curve shows that the blasting integrity rate of the coal decreased to 0.75 at $7.2-7.3 \mathrm{~m}$ from the blasting hole, i.e., the effective influence radius of the blasting hole was in the range $7.2-7.3 \mathrm{~m}$ under the working conditions. 
The rock mass intactness index $K_{v}=0.55$ is used as the criterion for comparing relatively intact and relatively broken rock mass, i.e., if the intactness index is less than 0.55 , this indicates a significant increase in the fracture of rock mass. Similarly, the blasting integrity rate of coal $k_{v}=0.55$ was used as the index of the effective cracking range for the blasting. The fitting curve shows that the blasting integrity rate of the coal will decrease to 0.55 in the range of $3.3-3.4 \mathrm{~m}$ from the blasting hole, i.e., the effective cracking radius of the blasting under the working condition was further determined in the range of 3.3-3.4 $\mathrm{m}$.

\section{Test and Results Analysis of Controlled Presplitting Blasting through Strata for Gas Drainage in Coal Roadway Strips}

The test was conducted on the upper part of the $\mathrm{Wu}_{9,10}-14160$ roadway strip near the gas-drainage roadway. The crossing boreholes were drilled from the gas-drainage roadway to the bottom of the $\mathrm{Wu}_{9,10}$ coal seam, and controlled from a distance of $15 \mathrm{~m}$ from the $\mathrm{Wu}_{9,10}$ -14160 roadway (as shown in Figure 8). The depths of the drainage hole ranged from 18 to $32 \mathrm{~m}$, with a pore diameter of $94 \mathrm{~mm}$. The holes were staggered. There were five drainage holes in each group, and the distances of the strike and dip between the adjacent drilling holes were $1 \mathrm{~m}$ and $4.7 \mathrm{~m}$, respectively. Based on the drilling parameters presented in Figure 8 and Table 3, the construction area of the four groups of drainage holes was used as the test area, followed by I, II, III, and IV. Finally, a parallelogram drainage network with a dimension of $4 \mathrm{~m} \times 4.8 \mathrm{~m}$ was created in the coal seam floor, as shown in Figure 9. To prevent the borehole outside the test area from influencing the gas-drainage effect, blank bands with a length of $4 \mathrm{~m}$ were placed on the sides of Groups I and IV.

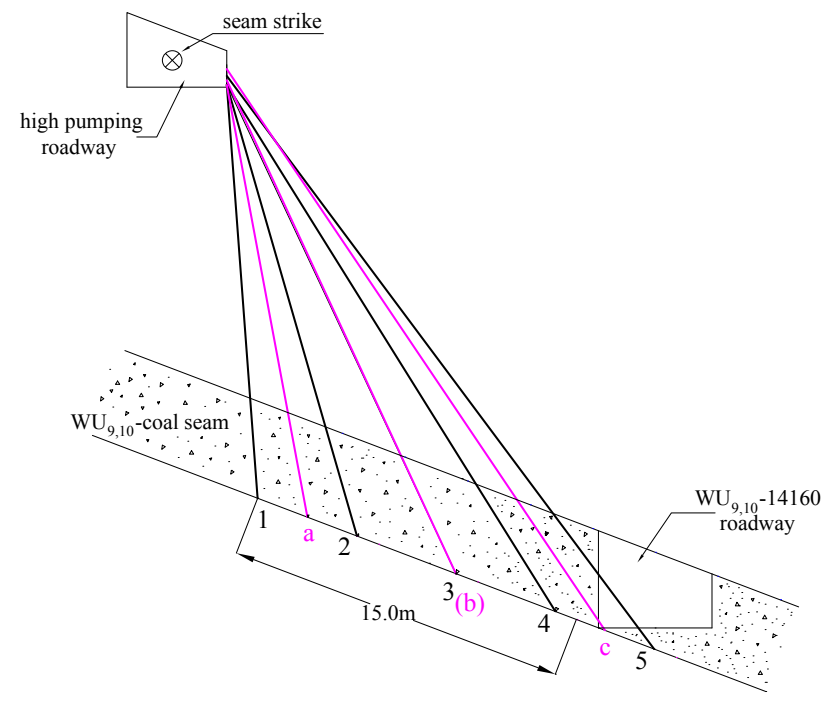

Figure 8. Cross-section of position of holes.

Table 3. Drilling parameters of controlled presplitting blasting.

\begin{tabular}{ccccc}
\hline Number & Dip Angle $\left(^{\circ}\right)$ & Depth $(\mathbf{m})$ & Orifice Height $(\mathbf{m})$ & Purpose \\
\hline 1 & -86 & 18.34 & 0.1 & Drainage \\
2 & -74 & 20.76 & 0.1 & Drainage \\
3 & -65 & 23.85 & 0.1 & Drainage \\
4 & -58 & 27.40 & 0.1 & Drainage \\
5 & -53 & 31.56 & 0.5 & Drainage \\
a & -80 & 19.40 & 0.1 & Blasting \\
b & -65 & 24.00 & 0.3 & Blasting \\
$\mathrm{c}$ & -56 & 29.90 & 0.8 & Blasting \\
\hline
\end{tabular}




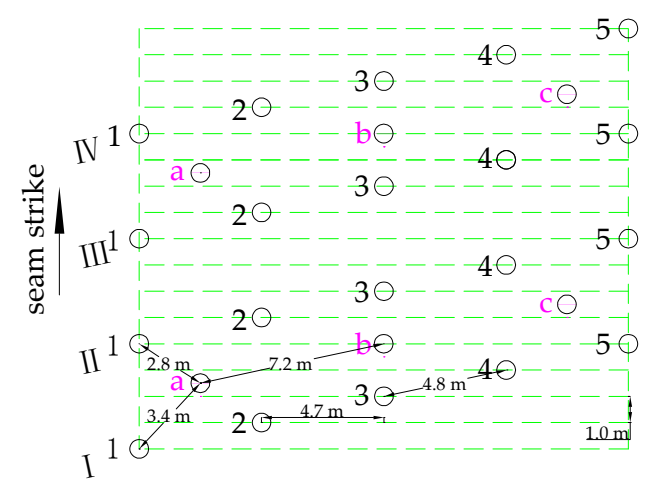

Figure 9. Borehole bottom position of controlled presplitting blasting holes.

Based on the analysis conducted in Section 3.3, the two groups of drainage holes were considered as a test group. Three blasting holes were arranged in each test group, which were created based on the parameters listed in Table 3. At the bottom of the holes, in groups I and II as examples, blasting hole a was located at the geometric center of the parallelogram comprising I1-I2-II2-II1. Blasting hole $\mathbf{b}$ was located at the center of the line comprising I3-II3, and blasting hole $\mathbf{c}$ was located at the geometric center of the parallelogram comprising I4-I5-II5-II4. Thus, each drainage hole was located within the effective cracking range $(3.4 \mathrm{~m})$ of the adjacent blasting holes, and each blasting hole was located within the effective influence range $(7.2 \mathrm{~m})$ of the adjacent ones (as shown in Figure 9). The charging and sealing methods for the blasting holes were the same as that described in Section 3.2. To prevent methane detonation, the blasting holes were detonated one at a time in the order $\mathbf{a} \rightarrow \mathbf{b} \rightarrow \mathbf{c}$. Groups I and II were grouped together and groups III and IV were grouped together. The flowmeter and concentration meter were installed on the drainage branch to monitor the changes in gas extraction parameters before and after blasting.

Figure 10 shows the amount of pure gas extracted from each group before and after blasting. In groups I and II, the average amount of pure gas extracted in a week before blasting was approximately $0.0109 \mathrm{~m}^{3} / \mathrm{min}$, with a maximum of $0.0137 \mathrm{~m}^{3} / \mathrm{min}$. After blasting, the maximum amount of pure gas extracted was $0.0424 \mathrm{~m}^{3} / \mathrm{min}$, which is 3.09 times the amount before blasting. The average amount of pure gas extracted in the first week was approximately $0.0353 \mathrm{~m}^{3} / \mathrm{min}$, which was 3.24 times that before blasting. In groups III and IV, the average amount of pure gas extracted in a week before blasting was approximately $0.0166 \mathrm{~m}^{3} / \mathrm{min}$, with a maximum of $0.0190 \mathrm{~m}^{3} / \mathrm{min}$. After blasting, the maximum amount of pure gas extracted was $0.0482 \mathrm{~m}^{3} / \mathrm{min}$, which is 2.54 times higher than that before blasting. The average amount of pure gas extracted in the first week was approximately $0.0428 \mathrm{~m}^{3} / \mathrm{min}$, which is 2.58 times the amount that before blasting. Thus, the efficiency of gas extraction improved.

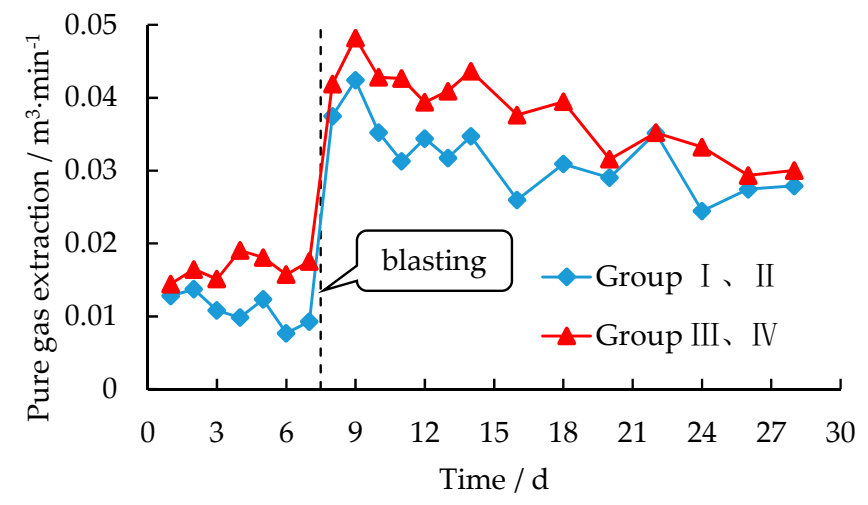

Figure 10. Variation curves of pure gas extraction from boreholes. 


\section{Conclusions}

Based on controlled presplitting blasting field tests conducted through strata, the influence radii resulting from this type of blasting under working condition were obtained by analyzing the variations in stress and longitudinal-wave velocity for different blasting ranges. By optimizing the drilling arrangement, the efficiency of gas extraction from the coal roadway strips was improved. The conclusions of this study are summarized as follows.

(1) Different stresses and fragmentation of the coal body were observed at different locations from the blasting hole after blasting. Owing to the effects of the explosion wave and explosion gas, the coal body was rapidly compressed and damaged at a distance of $1 \mathrm{~m}$ from the blasting hole. Thus, the coal exhibited negligible bearing capacity. At a distance of 1-3 $\mathrm{m}$ from the blasting hole, the coal body was also compressed, but a certain amount of coal bearing capacity remained. The coal at a distance of $5 \mathrm{~m}$ away from the blasting hole was not compressed significantly and the stress largely remained constant.

(2) The variations in longitudinal-wave velocity in the coal seam before and after blasting can be used to represent the degree of coal-fissure development. The blasting integrity rate of coal $k_{v}$ was defined to characterize the effects of blasting on the coal-seam fracturing process. By fitting $k_{v}$ with the blasting distance $r$ function, the effective cracking and effective influence radii of the blasting under this working condition were predicted to be in the range $3.3-3.4 \mathrm{~m}$ and $7.2-7.3 \mathrm{~m}$, respectively.

(3) The borehole layout was optimized; the drainage and blasting holes were arranged in a staggered manner within the effective cracking and effective influence ranges of the adjacent blasting holes, respectively. The amount of pure gas extracted after blasting increased by 1.54-2.24 times the amount before blasting. Moreover, the efficiency of gas extraction from coal roadway strips was improved.

Acknowledgments: This study was financially supported by National Natural Science Foundation of China (51434003, 51374256) and Graduate Scientific Research and Innovation Foundation of Chongqing, China (CYS16012, CYB16030). The authors are grateful for the No. 8 coal mine, Pingdingshan Tianan Coal Co. Ltd., China for providing field test sites.

Author Contributions: Dongming Zhang conceived and designed the experiments; Zhenlong Song measured the impact radius of the blasting; Chao Liu and Dongling Sun performed the controlled presplitting blasting through strata tests for evaluating the gas-drainage effect in coal roadway strips; Zhicheng Xie and Minghui Li analyzed the data; and Zhicheng Xie wrote the paper.

Conflicts of Interest: The authors declare no conflict of interest.

\section{References}

1. Wang, L.; Liu, S.M.; Cheng, Y.P.; Yin, G.Z.; Zhang, D.M.; Guo, P.K. Reservoir reconstruction technologies for coalbed methane recovery in deep and multiple seams. Int. J. Min. Sci. Technol. 2017, 27, 277-284. [CrossRef]

2. Wang, H.F.; Cheng, Y.P.; Wang, L. Regional gas drainage techniques in Chinese coal mines. Int. J. Min. Sci. Technol. 2012, 22, 873-878.

3. Fan, C.J.; Li, S.; Luo, M.K.; Du, W.Z.; Yang, Z.H. Coal and gas outburst dynamic system. Int. J. Min. Sci. Technol. 2017, 27, 49-55. [CrossRef]

4. Wang, L.; Cheng, Y.P.; Ge, C.G.; Chen, J.X.; Li, W.; Zhou, H.X.; Wang, H.F. Safety technologies for the excavation of coal and gas outburst-prone coal seams in deep shafts. Int. J. Rock Mech. Min. Sci. 2013, 57, 24-33. [CrossRef]

5. Zhou, H.X.; Zhang, R.; Cheng, Y.P.; Dai, H.; Ge, C.G.; Chen, J.X. Methane and coal exploitation strategy of highly outburst-prone coal seam configurations. J. Nat. Gas Sci. Eng. 2015, 23, 63-69. [CrossRef]

6. Yuan, Z.G.; Ren, M.Q.; Shen, Y.H. Hydraulic fracturing technology by drilling through strata for outburst prevention in coal roadway strips and its application. J. Chongqing Univ. 2016, 39, 72-78. (In Chinese)

7. Xu, J.Z.; Zhai, C.; Qin, L. Mechanism and application of pulse hydraulic fracturing in improving drainage of coalbed methane. J. Nat. Gas Sci. Eng. 2017, 40, 79-90. [CrossRef] 
8. Lin, B.Q.; Yan, F.Z.; Zhu, C.J.; Zhou, Y.; Zou, Q.L.; Guo, C.; Liu, T. Cross-borehole hydraulic slotting technique for preventing and controlling coal and gas outbursts during coal roadway excavation. J. Nat. Gas Sci. Eng. 2015, 26, 518-525. [CrossRef]

9. Zhang, C.; Lin, B.Q.; Zhou, Y.; Zhai, C.; Zhu, C.J. Study on "fracturing-sealing" integration technology based on high-energy gas fracturing in single seam with high gas and low air permeability. Int. J. Min. Sci. Technol. 2013, 23, 841-846. [CrossRef]

10. Singh, P.K.; Roy, M.P.; Paswan, R.K. Controlled blasting for long term stability of pit-walls. Int. J. Rock Mech. Min. Sci. 2014, 70, 388-399. [CrossRef]

11. Cao, S.G.; Li, Y.; Liu, Y.B.; Zhang, L.Q.; Xu, A.M. Effectiveness analysis of methane-drainage by deep-hole controlled pre-splitting blasting for preventing coal and gas outburst. J. Coal Sci. Eng. 2009, 15, 166-170. [CrossRef]

12. Liu, J.; Liu, Z.G.; Cai, F. Experiment study on pre-cracking blasting and permeability improvement effect with deep borehole for seam opening of crosscut. Coal Sci. Technol. 2011, 39, 30-32. (In Chinese)

13. Liu, J.; Liu, Z.G.; Gao, K. An experimental study of deep borehole pre-cracking blasting for gas pre-drainage on a mine heading roadway in a low permeability seam. AGH J. Min. Geoeng. 2012, 36, 225-232.

14. Liu, J.C.; Wang, H.T.; Yuan, Z.G.; Fan, X.G. Experimental Study of Pre-splitting Blasting Enhancing Pre-drainage Rate of Low Permeability Heading Face. Procedia Eng. 2011, 26, 818-823.

15. Liu, J.; Liu, Z.G.; Xue, J.H.; Gao, K.; Zhou, W. Application of deep borehole blasting on fully mechanized hard top-coal pre-splitting and extraction in the special thick seam. Int. J. Min. Sci. Technol. 2015, 25, 755-760. [CrossRef]

16. Lai, X.P.; Shan, P.F.; Cao, J.T.; Sun, H.; Suo, Z.Y.; Cui, F. Hybrid assessment of pre-blasting weakening to horizontal section top coal caving (HSTCC) in steep and thick seams. Int. J. Min. Sci. Technol. 2014, 24, 31-37. [CrossRef]

17. Zhou, S.C.; Li, D.; Zhang, F.W. Optimization analysis of drilling layout based on blasting releasing pressure and its application. Chin. J. Rock Mech. Eng. 2013, 32, 807-813. (In Chinese)

18. Zhu, W.C.; Wei, C.H.; Li, S.; Wei, J.; Zhang, M.S. Numerical modeling on destress blasting in coal seam for enhancing gas drainage. Int. J. Rock Mech. Min. Sci. 2013, 59, 179-190. [CrossRef]

19. Li, C.Y.; Kang, L.J.; Qi, Q.X.; Mao, D.M.; Liu, Q.M.; Xu, G. The numerical analysis of borehole blasting and application in coal mine roof-weaken. Procedia Earth Planet. Sci. 2009, 1, 451-459.

20. Wang, F.T.; Tu, S.H.; Yuan, Y.; Feng, Y.F.; Chen, F.; Tu, H.S. Deep-hole pre-split blasting mechanism and its application for controlled roof caving in shallow depth seams. Int. J. Rock Mech. Min. Sci. 2013, 64, 112-121. [CrossRef]

21. Gong, M.; Xiong, B.L.; Wang, C.H.; Wang, H. Discussion on distribution of dynamic stress and gas draining efficiency in coal seams by blasting through layers of coal-rock. Chin. J. Rock Mech. Eng. 2012, 31, 2899-2996. (In Chinese)

22. Gong, M.; Wen, B.; Wang, D.L. Numerical simulation of blasting through strata for gas drainage in Nantong coal mine and its application. Rock Soil Mech. 2012, 33, 1822-1828. (In Chinese)

23. Liu, Z.G.; Zhang, Y.H.; Huang, Z.A.; Gao, Y.K.; Zhang, Y.F. Numerical simulating research on orifice pre-splitting blasting in coal seam. Procedia Eng. 2012, 45, 322-328. [CrossRef]

24. Zhang, D.M.; Qi, X.H.; Yin, G.Z.; Zheng, B.B. Coal and rock fissure evolution and distribution characteristics of multi-seam mining. Int. J. Min. Sci. Technol. 2013, 23, 835-840. [CrossRef]

25. Li, M.H.; Cao, J.; Li, W.P. Stress and damage induced gas flow pattern and permeability variation of coal from Songzao Coalfield in Southwest China. Energies 2016, 9, 351. [CrossRef]

26. Yin, G.Z.; Li, M.H.; Wang, J.G.; Xu, J.; Li, W.P. Mechanical behavior and permeability evolution of gas infiltrated coals during protective layer mining. Int. J. Rock Mech. Min. Sci. 2015, 80, 292-301. [CrossRef]

27. Cai, F.; Liu, Z.G.; Zhang, C.J.; Lin, B.Q. Numerical simulation of improving permeability by deep-hole pre-splitting explosion in loose-soft and low permeability coal seam. J. China Coal Soc. 2007, 32, 499-503. (In Chinese)

28. Hemmati Nourani, M.; Taheri Moghadder, M.; Safari, M. Classification and assessment of rock mass parameters in Choghart iron mine using P-wave velocity. J. Rock Mech. Geotech. Eng. 2017, 9, 318-328. [CrossRef] 
29. Cheng, L.; Wang, Y.; Zhang, Y.G.; Zhao, H.Z. The present situation and prospect of the acountic properties research in coal. Prog. Geophys. 2013, 28, 452-461. (In Chinese)

30. The National Standards Compilation Group of Peoples Republic of China. GB/T 50218-2014 Standard for Engineering Classification of Rock Masses; China Planning Press: Beijing, China, 2014. (In Chinese) 